EPiC Series in Computing
Volume 78, 2021, Pages 136-147
Proceedings of the European Univer-
sity Information Systems Conference 2021

\title{
Emergency Remote Teaching and Online Exams at the National and Kapodistrian University of Athens during the COVID-19 Pandemic
}

\author{
Konstantinos Tsibanis ${ }^{1,2}$ and Pantelis Balaouras ${ }^{1,2}$ \\ ${ }^{1}$ Network Operations Centre - National and Kapodistrian University of Athens, Greece \\ ${ }^{2}$ Department of Informatics and Telecommunications - National and Kapodistrian University of \\ Athens, Greece \\ ktsibanis@uoa.gr, balaouraedi.uoa.gr
}

\begin{abstract}
The outbreak of COVID-19 pandemic has caused a great disruption in higher education worldwide. Traditional face to face teaching had to change suddenly and in an unplanned way in emergency remote teaching, a temporary shift of instructional delivery to an alternate delivery mode due to crisis circumstances. This paper presents the transition to emergency remote teaching at the National and Kapodistrian University of Athens (NKUA) during the COVID-19 pandemic and explores the challenges and the opportunities in several aspects, technological, pedagogical, organizational, individual and social, based on lessons learned.
\end{abstract}

Keywords: Higher education; emergency remote teaching; technological challenges; pedagogical challenges; online exams; open eclass platform; nkua; covid-19;

\section{Introduction}

The coronavirus (COVID-19) was declared as a global pandemic in March 2020 and social distancing was adopted in many countries to contain the problem. Ministries of education in numerous countries around the world recommended or made mandatory the shift to an online education model to prevent the spread of the virus. In this unprecedented situation, Higher Education Institutions (HEIs) had to decide about how to continue teaching and learning while keeping their faculty, staff, and students safe. Many institutions opted to cancel all face-to-face classes, including labs and other learning experiences, and asked faculty members to move their courses online. 
Normally, moving instruction online can enable the flexibility of teaching and learning anywhere, anytime, but the speed with which this move to online instruction was expected to happen was unprecedented and challenging. Although specialized support personnel were available to help faculty members to implement online courses, in this situation, these individuals and teams were not able to offer the same level of support to all faculty in such a narrow preparation window.

What we know from research is that typical planning, preparation, and development time for a fully online university course is six to nine months before the course is delivered. In contrast to experiences that are planned from the beginning and designed to be online, emergency remote teaching (ERT) is a temporary shift of instructional delivery to an alternate delivery mode due to crisis circumstances. It involves the use of fully remote teaching solutions for education that would otherwise be delivered faceto-face. The primary objective in these circumstances is not to re-create a robust educational ecosystem but rather to provide temporary access to instruction in a manner that is quick to set up and is reliably available.

In this paper we present how the National and Kapodistrian University of Athens (NKUA) has dealt with the challenges of shifting into emergency remote teaching (ERT) and online exams during COVID19 pandemic.

\section{The case of National and Kapodistrian University of Athens}

National and Kapodistrian University of Athens (NKUA) is a research University that has attained recognition as an institution of educational and scientific excellence. It is the largest state institution of higher education in Greece, and among the largest universities in Europe. According to the «Top Universities by Top Google Scholar Citations» rankings by Webometrics, the National and Kapodistrian University of Athens is ranked 41st in the world, 10th in Europe. It offers a wide range of study areas; 68,500 students are currently enrolled in 43 undergraduate and 200 postgraduate programs leading to a Master's or Doctoral degree.

National and Kapodistrian University of Athens (NKUA) has adopted technology into educational process for more than 20 years. An e-learning ecosystem of online tools and resources is supported based mainly on open software and open technologies like Learning Management System (Open eClass), Video on Demand and Video Streaming platform (Open Delos), Teleconferencing tools (BBB, Webex, Zoom, Google Meet), Survey platform (Lime Survey), Collaboration platform (Synergasia) and other digital tools for teaching and learning. In addition, specialized personnel is available to help faculty members to design, implement and support online courses.

However, on March 2020 COVID-19 pandemic crisis caused a massive disruption in the way NKUA was functioning and delivering its courses. The approach that was followed for a rapid shift from the traditional face to face teaching in emergency remote teaching (ERT) was based on previous experiences and the established infrastructure in order to respond to the new requirements in a short period of time. NKUA's specialized support personnel prepared and communicated to faculty members and students through a remote-teach guidelines website and a series of webinars a number of different scenarios of how to create and deliver online courses and online exams in an easy and effective way. In the next chapters of this paper, remote teaching and online assessment scenarios are presented and analyzed in detail.

NKUA's e-learning ecosystem served as a basis for supporting emergency remote teaching. Technological infrastructures were evaluated and technically strengthened with greater computing capabilities and storage capacity in order to cope with the new increased demands. IT groups undertook in shifts the obligation to monitor the e-learning services and immediately intervene when a technical problem occurred. The helpdesk service also extended the operating hours from $8 \mathrm{am}$ to $8 \mathrm{pm}$ in order to better support the online educational process. 


\section{The E-learning Ecosystem at National and Kapodistrian University of Athens}

National and Kapodistrian University of Athens (NKUA) is one of the pioneer Universities in Greece and in Europe in incorporating technology into the educational process for more than 20 years. NKUA has a comprehensive e-learning ecosystem that consists of online platforms and services, mainly based on open source software and technologies. The core components of this e-learning ecosystem is Open eClass, an open source LMS (Learning Management System) that orchestrates the learning process and the online communication and Open Delos a Video on Demand and Video Streaming platform. In addition, teleconferencing tools and services (BBB, Webex, Zoom, Google Meet), analytics platform (Matomo), survey platform (Lime Survey), collaboration platform (Synergasia), open courses platform (Opencourses) and other digital tools for teaching and learning are part of NKUA's e-learning ecosystem.

Open eClass (openeclass.org) is a multilingual open source learning management system (LMS) designed and developed in-house under the umbrella of the Greek Universities Network (GUnet) since 2003. It provides an effective platform for online learning, teaching and course delivery used by the two thirds of the higher education institutions in Greece with over than 400.000 users (students and teaching staff), all public schools (eclass.sch.gr) with over than 1.300 .000 users (pupils and teaching staff) and countless more educational organizations. Open eClass is an easy to use, secure and flexible platform that helps educators to create online courses and support all instructional scenarios like blended learning, distance education, flipped classroom, asynchronous collaborative learning, self-paced learning, etc. During pandemic, Open eClass was the core platform for sharing online educational materials, for learning assessment and for the communication and collaboration with students. In addition, new features for online communication and online exams were incorporated into the platform. NKUA's Open eClass installation (eclass.uoa.gr) supports more than 9.700 online courses (undergraduate and postgraduate) and is addressed to more than 70.000 users.

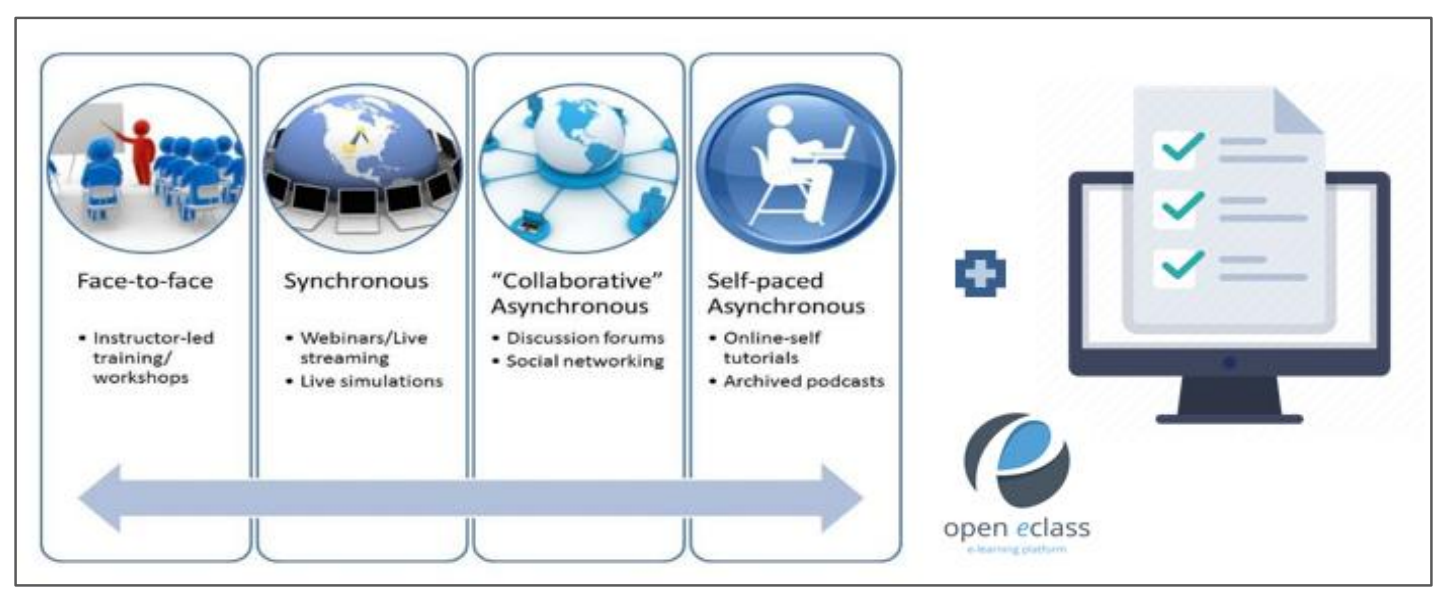

Figure 1. Transition to emergency remote teaching

The synchronous remote teaching process was supported by the Video on Demand and Video Streaming platform (Open Delos) and the Teleconferencing tools (BBB, Webex, Zoom and Google Meet). These services were integrated with Open eClass platform and NKUA's identity service to give personalized access to both faculty members and students through online courses. 
Open Delos platform (opendelos.org) consists of a rich media and lecture platform for education designed and developed in-house under the umbrella of the Greek Universities Network (GUnet) since 2014. It supports both live streaming of lectures from classrooms and amphitheaters equipped with HD IP cameras and audiovisual systems as well as video on demand provision of recorded lectures. Content creators may also upload slides and synchronize them with the video lectures as well as edit video online. More than 25 Greek Universities have installed this platform. NKUA' Open Delos platform (delos.uoa.gr) hosts more than 30.000 videos and supports live streaming from 55 classrooms and amphitheaters.

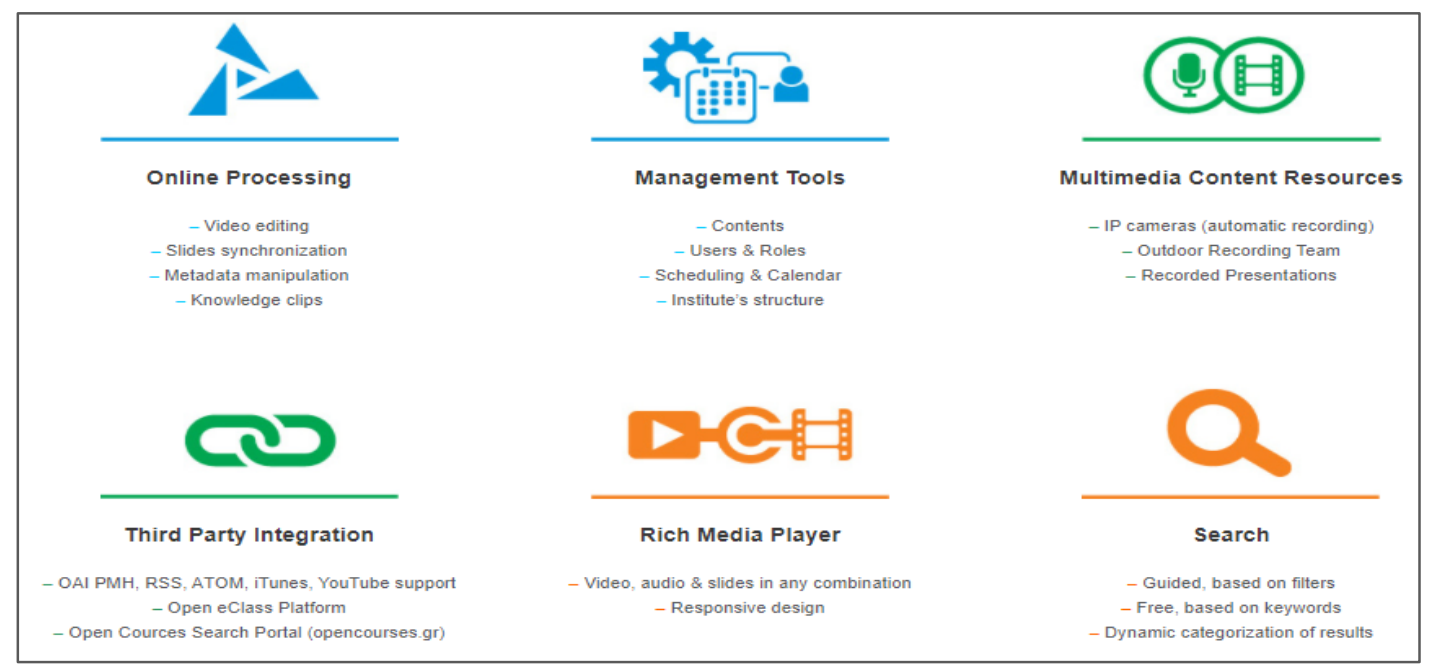

Figure 2. Supported functionality by Open Delos Platform

In addition, a number of peripheral digital tools for teaching and learning are part of NKUA's elearning ecosystem. BigBlueButton (BBB) is an open source web conferencing and online teaching platform integrated with Open eClass LMS platform. Webex, Zoom and Google Meet are commercial enterprise solutions that support web conferencing and online meetings. Matomo is a free and open source web analytics platform. Lime survey is an open source platform for creating and supporting online surveys and questionnaires. Finally, Synergasia is an open source collaboration platform that supports teams to work together on projects or other group tasks.

The last piece of NKUA's e-learning ecosystem puzzle is the Open Courses platform developed in the context of the Open Courses Program (project.opencourses.gr) under which more than 3.700 Open Courses were developed by the Greek Higher Education Institutions, with more than 1.100 Open Courses being accompanied with the full series of recorded video lectures. This content is hosted by the Open eClass and Open Delos platforms. Open courses and the full series of video lectures were a valuable legacy for the Universities in Greece and have been widely used for remote teaching and learning during the pandemic.

\section{Remote Teaching Scenarios at National and Kapodistrian University of Athens}

Emergency remote teaching was formed in response to the pandemic. The situation was different from a well-planned traditional method of online learning as it was unexpected and unprecedented for 
faculty members, students, and institutions. For the first time all students were required to take all their classes online and all faculty members had to teach online. For this reason, emergency remote teaching can be considered as a temporary teaching solution to an emergent problem.

In this crisis situation NKUA reacted fast and effectively. A group of specialized personnel in elearning technologies, IT infrastructure, pedagogical aspects and administrative / legal issues was appointed in order to provide remote teaching and learning scenarios in a manner that is fast to set up and is reliably available during the emergency. This group of experts had to cope with several technological, pedagogical and social challenges but very soon, in two weeks, they set up a complete solution based on the existing infrastructure, experiences and skills. The pedagogical approach of the educational process was divided into two parallel processes: a) the learning and the asynchronous communication process and $b$ ) the synchronous remote teaching process.

The learning and asynchronous communication process was supported by NKUA's Learning Management System (Open eClass). The synchronous remote teaching process was supported by four (4) main scenarios that were prepared, based on audience size and the digital readiness of each course. For each scenario the common ground was the exploitation of Open eClass LMS platform for uploading slides, reading materials, online self-assessment activities, assignments and quizzes as well as communication with the students via the announcement and messages tools of the platform, e.g., announcement of the link for the videoconference or the video lectures of the course. The following list highlights the encountered remote teaching scenarios at the National and Kapodistrian University of Athens.

\section{Scenario A: Remote Teaching with recorded lectures}

In this scenario, faculty members exploited the recorded lectures developed under the aforementioned NKUA's Open Courses Program. Students were asked to watch the online video lectures synchronized with slides while video conferencing services were used by the faculty members for keeping contact with students and giving them directions. All NKUA's digital courses were available in the Open eClass LMS platform and followed a uniform instructional design structured with course units. Each course unit contained learning material, e.g., slides, theory, exercises, assignments and links to the recorded video lectures available in NKUA's video platform Open Delos.

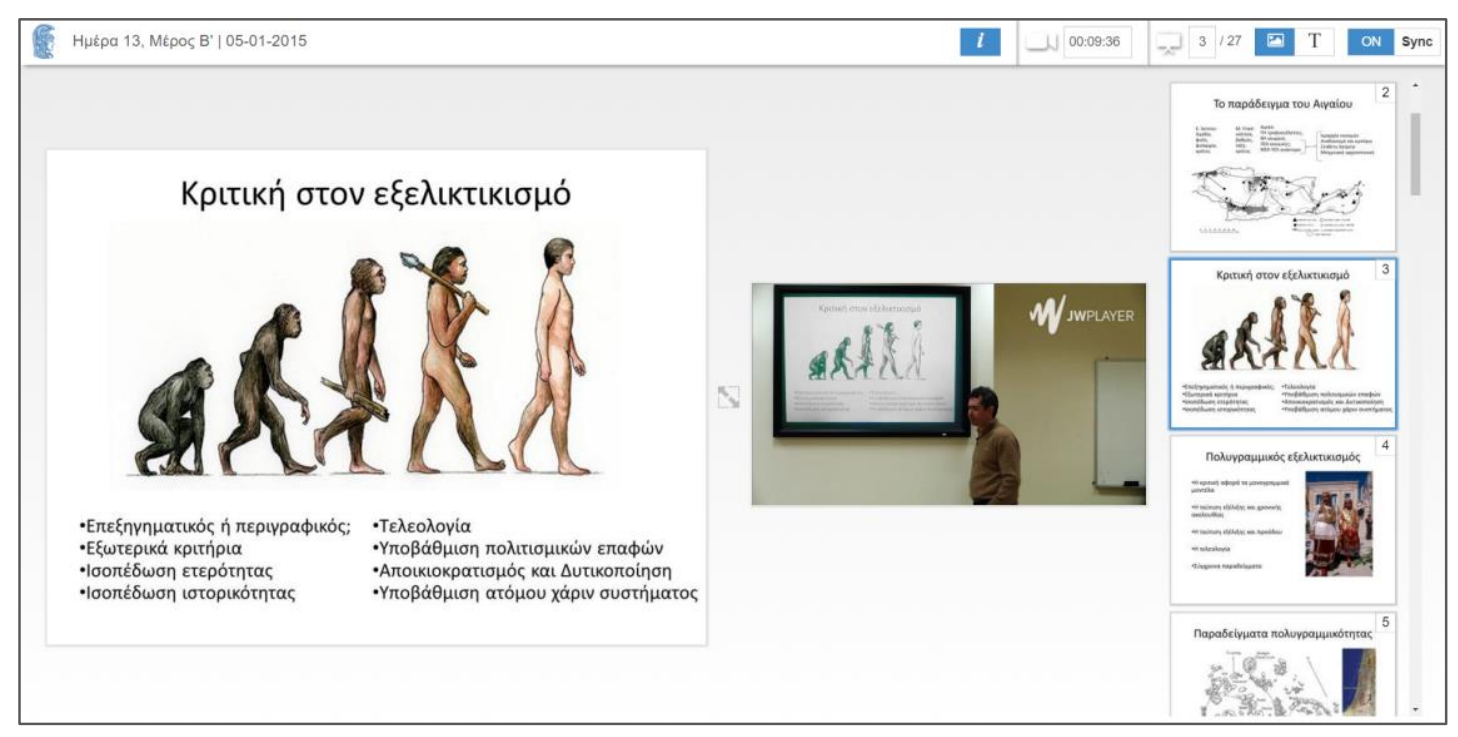

Figure 3. Example of video lecture with synchronized slides 


\section{Scenario B: Remote Teaching with live streaming - 250+ participants}

For online courses with more than 250 participants (large audience), the proposed remote teaching scenario was based on a video streaming service (one-way communication) through Open Delos platform. Faculty members were able to stream their lectures from a properly equipped University classroom with a high-definition IP camera, microphone installation, multimedia pc and big screens. Communication with students was supported by the online chat tool in Open eClass course. This scenario was popular to faculty members who wanted to use whiteboard for their lectures, mainly from Schools of Science and Financing. These lectures were automatically recorded and asynchronous available via the Open Delos and Open eClass platforms. Teaching staff who were giving their lectures from home, were proposed to use NKUA's YouTube live streaming service and deliver those streams through Open eClass courses.

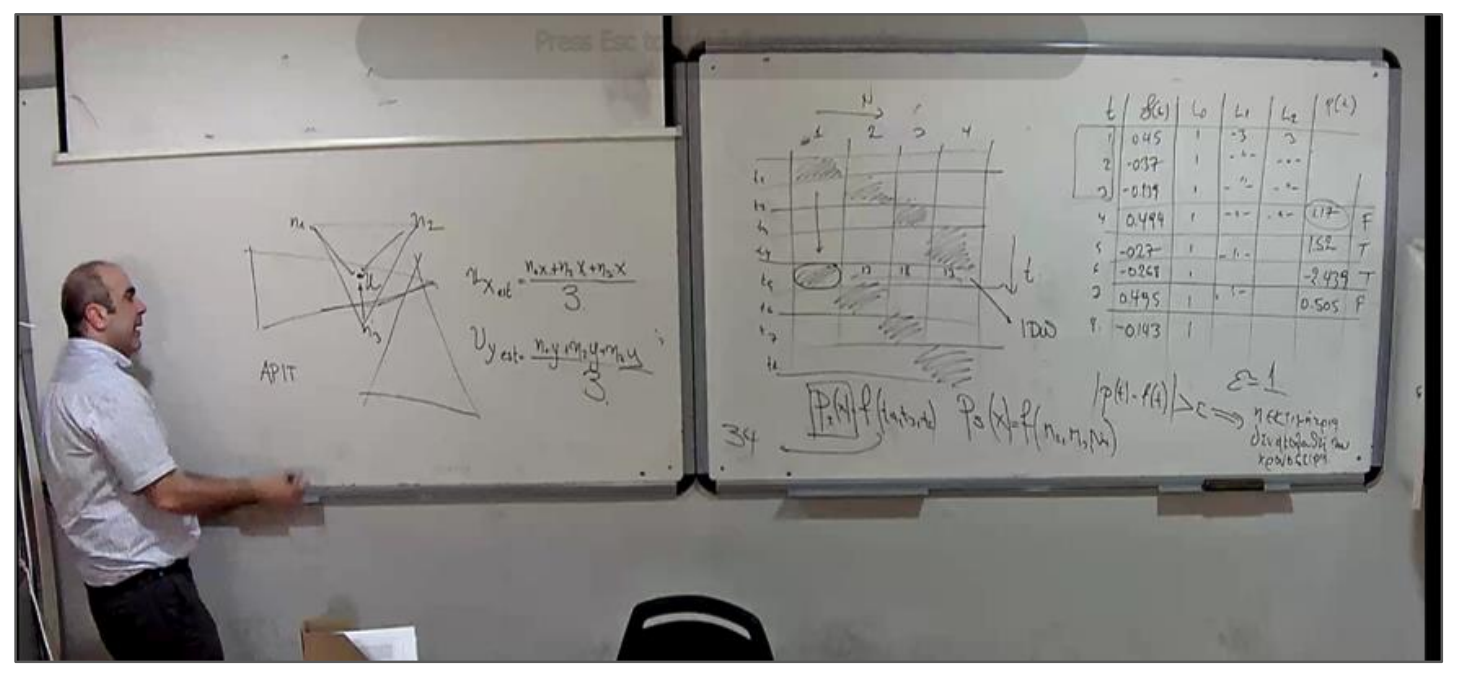

Figure 4. Example of live streaming at NKUA

\section{Scenario C: Remote Teaching with video conferencing services - 50 to 250 participants}

For online courses with 50 to 250 participants (medium audience), the proposed remote teaching scenario was based on commercial videoconferencing tools (Webex, Zoom and Google Meet - cloud platforms) where application sharing and two-way video and audio communication with students was supported. In the first period of the pandemic (March 2020 - July 2020) the teaching staff used all the available video conferencing tools and evaluated them in terms of user experience and functionality. However, in the second period of pandemic NKUA got licenses of Cisco Webex in order to provide a common tool for facilitating remote teaching and simplifying the technical support.

\section{Scenario D: Remote Teaching with open source video conferencing tools - 50-participants}

For online courses with less than 50 participants (small audience), the proposed remote teaching scenario was based on the open source teleconferencing tool BigBlueButton (BBB), an on premises installed platform where application sharing and two-way video and audio communication with students were supported. This scenario mainly addressed postgraduate courses.

NKUA's specialized support personnel undertook the important task to communicate the aforementioned scenarios to faculty members and students. For this reason, a Remote Teaching online open course (http://teachremote.uoa.gr/) was rapidly developed on the Open eClass LMS platform. Aim 
of this course was to give a clear and comprehensible presentation of all remote teaching scenarios with pedagogical and technical guidelines, case studies, simple examples and a series of webinars. In addition, a number of step by step how-to video tutorials with technical details and useful examples were prepared. All these scenarios and online material were communicated through GUnet and the Ministry of Education to all Higher Education Institutes in Greece.

However, the most important challenge in this sudden shift to emergency remote teaching at NKUA because of the COVID-19 outbreak was not the preparation stage of the scenarios, the online material and the infrastructure but the implementation of the remote teaching in practice by the faculty members. In practice it was proved that NKUA's digital readiness and the early adoption of digital culture in education from faculty members and students were the two important factors that contributed positively to the successful implementation of remote teaching for two academic semesters, spring 2020 (Mar 2020 - Jul 2020) and winter 2021 (Oct 2020 - Feb 2021).

Especially during the first pandemic period (Mar 2020 - Jul 2020), in a total of 1,762 undergraduate courses, 1,500 theoretical courses were fully covered by remote teaching (86\%), 141 courses were covered only in terms of their theoretical part by remote teaching (8\%) and 121 courses were not taught due to the nature of the courses (6\%). At the same period in a total of 1,583 postgraduate courses, 1,361 theoretical courses were fully covered by distance teaching (86\%), 39 courses were covered only in terms of their theoretical part by distance teaching (3\%) and 183 courses were not taught due to the nature of the courses (11\%).

The following diagrams can reveal more useful conclusions about remote teaching at NKUA during the pandemic and the effectiveness of the proposed remote teaching scenarios. These diagrams present the usage of NKUA's e-learning services, and especially the usage of the Open eClass LMS platform during 3 periods, the pre-pandemic period from January 2018 to February 2020 (area C), the first pandemic period from March 2020 to Jul 2020 (area A) and the second period of pandemic from September 2020 to March 2021 (area B). By comparing these three areas, it can be obvious that during the pandemic periods the usage of NKUA's e-learning ecosystem has increased significantly. Figure 5 indicates that the average monthly number of visits in NKUA's eClass platform raised from 750.000 in the pre-pandemic period (area C) to 1.500 .000 during the first pandemic period (area A) and to 2.200.000 during the second pandemic period (area B). The same pattern appears in the diagram with the average network bandwidth consumed in NKUA's eClass platform but with higher rates of increase.
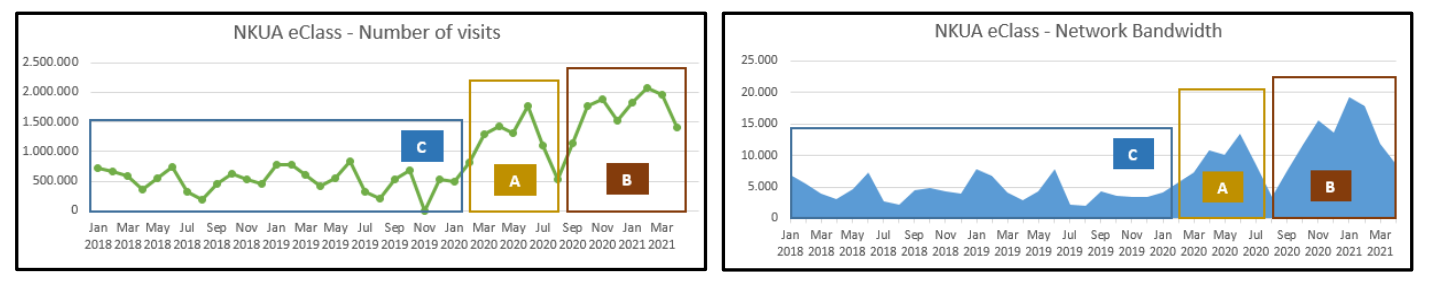

Figure 5. Number of visits and bandwidth (in GB) on NKUA's Open eClass LMS (eclass.uoa.gr)

This short quantitative analysis of data demonstrates that during the two pandemic periods the usage of NKUA's e-learning ecosystem has significantly increased. However, from this analysis as well as from other quantitative data concerning the usage of specific tools in LMS (messages, discussions, assignments, exercises, etc.) and the access to specific educational resources (videos, exercises, course files, etc.), interesting qualitative results can be retrieved. A general conclusion is that with the sudden digital transformation that took place in higher education during the pandemic, both students and faculty members have highly exploited institution's e-learning infrastructure and became accustomed to online learning and teaching. Attendance to synchronous lectures was above the usual average and furthermore, the interaction and communication with students was improved. 


\section{Online Exams at National and Kapodistrian University of Athens}

Following campuses closure and the sudden shift to online course delivery, Higher Education Institutions and faculty members had to face another challenge, the shift to online examinations. In this context, there was a limited capacity to change the format of the examinations because of legal or institutional requirements and also because of the little experience of assessing in online setting. At NKUA, a group of specialized personnel undertook the redesign of the examination procedures in order to support fair and reliable online exams for the first time. This redesign process took into account some important factors regarding the online setting of the exams such as pedagogical aspects, digital skills of students and faculty members, cheating and plagiarism issues, technological infrastructure and possible technical failures.

Student academic dishonesty, which in practice translates to cheating and plagiarism, was by far the most frequently discussed challenge in higher education with regard to the shift of examinations online. It is true that in online examinations the capacity to control students' actions is reduced. The solution of using online proctoring tools to supervise remote examinations was rejected because of the cost and several concerns related to students' privacy, security and data protection. The technical solution selected for the supervision and monitoring of the online exams was through the available web conferencing tools integrated with the NKUA's official identity system.

Another important issue for the online exams was to ensure fairness. In normal on-site exams, all students gather in the same room to take an exam under similar conditions (timing, available material, etc.). In online exams, students do not benefit from the same conditions. They often have different digital skills and levels of technological equipment (screens sizes, computer speed, bandwidth connection, etc.). A fair online exam should ensure that poorer technological equipment does not impair academic success.

In addition, an adequate and stable technical infrastructure is a key prerequisite for institutions to organize examinations online. Even with leading-edge technological infrastructure, the occurrence of technical failures during online examinations remains possible. It only takes one individual failure from one of the different interconnected sources (IT systems, LMS load, network failure, students' individual computers or local Internet providers) to threaten the validity of an online examination. Besides, this situation leaves room for students to complain and blame the technological system for a bad exam result. For this reason, technological requirements were kept to a minimum adequate level.

In light of the different challenges mentioned above, the new online examination strategies at NKUA relied on a combination of multiple solutions. The following list of assessment scenarios highlights the encountered solutions and recommendations at the National and Kapodistrian University of Athens to help faculty members and students to cope with online exams.

\section{Assessment Scenario A: Online assignments with antiplagiarism support}

The first assessment scenario was based on submitting online assignments within a strictly defined time frame with antiplagiarism support. This online assessment scenario resembles a lot the normal face-to-face on-site exams. Faculty members had to create one or more online assignments using Open eClass LMS platform and assign them to different group of students. Students had to answer a number of open type questions either online or by submitting a scanned handwritten text within a defined period. Plagiarism can occur in the context of an assignment based online exam with open type questions. For this reason, students were informed that a plagiarism detection software would be used during the assessment procedure. The examination procedure was electronically supervised and monitored by the faculty member and additional academic staff (teaching assistants or/and $\mathrm{PhD}$ students) using web conferencing tools integrated with NKUA's identity system. Students were divided in groups of 30 with the presence of a supervisor who also acted as a contact person for answering questions. 


\section{Assessment Scenario B: Online quizzes with different closed type questions}

The second assessment scenario based on online quizzes with different closed type questions. A sophisticated system for the preparation of dynamic sets of questions was implemented in Open eClass LMS platform, using question banks organized into thematic categories, shuffling entries, levels of difficulty and weights, thus rendering a personalized set of test for each candidate. This scenario required additional investment from exam developers as it implied designing and scoring a larger range of questions. It was important that the questions taken by different students measure the same learning outcomes and have the same level of difficulty to ensure the reliability and fairness of the evaluation. Students had to answer a personalized set of questions within a strictly defined time frame. Setting stricter time limits for the duration of written examinations is another way to prevent possible dishonest behaviors. The examination procedure was electronically supervised and monitored by the faculty member and additional academic staff (teaching assistants or/and $\mathrm{PhD}$ students) using web conferencing tools integrated with NKUA's identity system. Students were divided in groups of 30 with the presence of a supervisor who also acted as a contact person for answering questions.

\section{Assessment Scenario C: Online oral exams}

The third assessment scenario was the online oral exams. Online oral exams offer several advantages to limit student cheating, to cope with the risk of technical failure and ensure fairness. Yet, online oral exams require a significant time investment from faculty members, especially when they are in charge of assessing large groups of students. In this scenario, the examination committee consisting of 2-3 faculty members is appointing online groups of 3-5 students by using NKUA's official web conferencing tools. Students were previously informed for the group they participate, the exact date/time of the oral exam and the virtual room (web conference link) they have to log-in.

The sudden shift to online assessment at NKUA required a redesign of the student examinations in order to support fair and reliable online exams for the first time. Adapting student examinations to online administration required that institution and faculty carefully consider several parameters such as pedagogical aspects, students and faculty members digital skills, cheating and plagiarism issues, technological infrastructure and possible technical failures. In this respect, the recent shift towards online examinations at NKUA because of the COVID-19 outbreak lead to different examination models between the spring semester of 2020 (June 2020) and the winter semester 2021 (February 2021).

More specifically, student exams during the first period of the pandemic, i.e. on spring semester of 2020 (June 2020), followed a mixed approach (online and face to face). Having 1,526 undergraduate and 809 postgraduate courses $(2,335$ in total) to be assessed, $60 \%$ of them $(1,415)$ were conducted online and $40 \%$ were conducted with normal face-to-face exams following the proposed health protocols. Figure 7 shows the analytic numbers of the different exam scenarios followed during that period. It is important to notice that in 1,415 online exams only 4 of them faced a problem which represents a very small amount considering the short time of preparation and the lack of previous experience.

\begin{tabular}{|c|c|c|c|c|c|c|c|c|c|c|c|}
\hline & DNLINE EX & AMS OF U & NDERGRAD & JATE AND & POSTGRADU & ATE COUR & ES COND & UCTED UNTI & L 07/07/ & 020 (PERIOL & \\
\hline \multirow{3}{*}{ NKUA } & \multicolumn{5}{|c|}{ A. UNDERGRADUATE COURSES EXAMS SPRING 2020} & \multicolumn{5}{|c|}{ B. POSTGRADUATE COURSES EXAMS SPRING 2020} & \\
\hline & \multicolumn{5}{|c|}{ A. Undergraduate Courses (figures) } & \multicolumn{5}{|c|}{ B. Postgraduate Courses (figures) } & \multirow[b]{2}{*}{$\begin{array}{l}\text { Problem / } \\
\text { Complain }\end{array}$} \\
\hline & $\begin{array}{l}\text { Normal } \\
\text { Oral Exams }\end{array}$ & $\begin{array}{l}\text { Normal } \\
\text { Written } \\
\text { Exams }\end{array}$ & $\begin{array}{l}\text { Online } \\
\text { Oral Exams }\end{array}$ & $\begin{array}{l}\text { Online } \\
\text { Written } \\
\text { Exams }\end{array}$ & $\begin{array}{l}\text { Online with } \\
\text { Assignment }\end{array}$ & $\begin{array}{l}\text { Normal } \\
\text { Oral Exams }\end{array}$ & $\begin{array}{l}\text { Normal } \\
\text { Written } \\
\text { Exams }\end{array}$ & $\begin{array}{l}\text { Online } \\
\text { Oral Exams }\end{array}$ & \begin{tabular}{|l} 
Online \\
Written \\
Exams
\end{tabular} & $\begin{array}{l}\text { Online with } \\
\text { Assignment }\end{array}$ & \\
\hline SUBTOTALS & 105 & 435 & 246 & 461 & 279 & 45 & 335 & 81 & 211 & 137 & $4 / 0$ \\
\hline $\begin{array}{l}\text { TOTAL } \\
\text { A:UC/ B:PC }\end{array}$ & \multicolumn{5}{|c|}{1526} & \multicolumn{5}{|c|}{809} & \\
\hline
\end{tabular}

Figure 7. Online exams in spring semester 2020 (June 2021) 
However, all student exams during the second period of pandemic, on winter semester of 2021 (Feb 2021), followed the online approach. Having 1,772 undergraduate and 1,244 postgraduate courses (3,016 in total) to be assessed, all of them (100\%) were conducted online. Figure 8 presents the analytic numbers of the different exam scenarios followed during that period. It is important to notice that the majority of the faculty member prepared and successfully conducted online written exams $(1,887$ courses) based on online quizzes and only 5 out of 3,016 online exams faced a problem which is an insignificant percentage considering the short time of preparation and the lack of previous experience.

\begin{tabular}{|c|c|c|c|c|c|c|c|c|c|c|c|}
\hline \multicolumn{12}{|c|}{ NKUA - ONLINE EXAMS OF UNDERGRADUATE AND POSTGRADUATE COURSES CONDUCTED UNTIL 05/03/2021 (PERIOD B) } \\
\hline \multirow{3}{*}{ NKUA } & \multicolumn{5}{|c|}{ A. UNDERGRADUATE COURSES EXAMS SPRING 2020} & \multicolumn{5}{|c|}{ B. POSTGRADUATE COURSES EXAMS SPRING 2020} & \\
\hline & \multicolumn{5}{|c|}{ A. Undergraduate Courses (figures) } & \multicolumn{5}{|c|}{ B. Postgraduate Courses (figures) } & \multirow[b]{2}{*}{$\begin{array}{l}\text { Problem / } \\
\text { Complaint }\end{array}$} \\
\hline & \begin{tabular}{|l} 
Normal \\
Oral Exams
\end{tabular} & $\begin{array}{l}\text { Normal } \\
\text { Written } \\
\text { Exams }\end{array}$ & \begin{tabular}{|l} 
Online \\
Oral Exams
\end{tabular} & \begin{tabular}{|l|} 
Online \\
Written \\
Exams
\end{tabular} & \begin{tabular}{|l|l} 
Online with \\
Assignment
\end{tabular} & \begin{tabular}{|l} 
Normal \\
Oral Exams
\end{tabular} & \begin{tabular}{|l|} 
Normal \\
Written \\
Exams \\
\end{tabular} & \begin{tabular}{|l} 
Online \\
Oral Exams
\end{tabular} & $\begin{array}{l}\text { Online } \\
\text { Written } \\
\text { Exams }\end{array}$ & \begin{tabular}{|l} 
Online with \\
Assignment
\end{tabular} & \\
\hline SUBTOTALS & 0 & 0 & 306 & 1152 & 314 & 0 & 0 & 131 & 735 & 378 & $5 / 0$ \\
\hline $\begin{array}{l}\text { TOTAL } \\
\text { A:UC/B:PC }\end{array}$ & \multicolumn{5}{|c|}{1772} & \multicolumn{5}{|c|}{1244} & \\
\hline
\end{tabular}

Figure 8. Online exams in winter semester 2021 (Feb 2021)

\section{Conclusions}

This paper presents the transition to emergency remote teaching and online exams at the National and Kapodistrian University of Athens (NKUA) during the COVID-19 pandemic and explores the challenges and the opportunities in several aspects, technological, pedagogical, organizational, individual and social, based on lessons learned.

NKUA had already established, before the COVID-19 pandemic crisis, a comprehensive e-learning ecosystem. This ecosystem was the key factor to deal with the challenges of shifting to emergency remote teaching and online exams, fast and effectively. Practice proved that NKUA's digital readiness and the early adoption of digital culture in education from faculty members and students were two important factors that positively affected the successful design and implementation of remote teaching for two academic semesters, spring 2020 (Mar 2020 - Jul 2020) and winter 2021 (Oct 2020 - Feb 2021). It is true that the revenue of the transition to emergency remote teaching was the introduction to large scale of digital innovation in education. At the same time, this sudden transition to online teaching and learning highlighted a number of weaknesses. The quality of teaching and learning on the one hand and the admittedly lack of interactive digital educational content suitable for online learning on the other hand are two of the most important weaknesses that have been stressed out.

However, the shift to online examinations proved to be the biggest challenge for all higher education institutions in Greece. There was a limited capacity to change the format of the examinations because of legal or institutional requirements and also because of the little experience of assessing in online setting. In this context, NKUA redesigned the examination procedures in order to support fair and reliable online exams for the first time. This redesign process took into account several important factors regarding the online setting of the exams such as pedagogical aspects, students and faculty members digital skills, cheating and plagiarism issues, technological infrastructure and possible technical failures. The horizontal guideline across all proposed scenarios was to consider online exams as open book and open access to the internet exams. The overall results of the online exams at NKUA were encouraging both in terms of reliability / participation and in students' success ratio. 
The COVID-19 pandemic offered an opportunity to Higher Education for a broader digital transformation. Teaching and learning assessment will definitely change when the pandemic is over by adopting most of the potentials brought by digital educational technologies. New services, better infrastructure, more digital content, digital skills and experiences, online tools and new educational scenarios are part of the valuable heritage for the future.

\section{References / Citations}

Santiago Iglesias-Pradas, Angel Hernandez-García, Julian Chaparro-Pelaez, Jose Luis Prieto (2021). "Emergency remote teaching and students' academic performance in higher education during the COVID-19 pandemic: A case study", Computers in Human Behavior, 119, 106713, ISSN 07475632 .

Whittle, C., Tiwari, S., Yan, S. and Williams, J. (2020). "Emergency remote teaching environment: a conceptual framework for responsive online teaching in crises", Information and Learning Sciences, Vol. 121 No. 5/6, pp. 311-319. https://doi.org/10.1108/ILS-04-2020-0099.

Trine Jensen (2019). "Higher Education in the Digital Era: The Current State of Transformation Around the World", International Association of Universities (IAU) 2019 Research report. Retrieved from https://www.iau-aiu.net/Higher-Education-in-the-Digital-Era-The-Current-State-ofTransformation-Around.

Charles Hodges, Stephanie Moore, Barb Lockee, Torrey Trust and Aaron Bond (2020). "The Difference Between Emergency Remote Teaching and Online Learning”, Retrieved March 27, 2020, from: https://er.educause.edu/articles/2020/3/the-difference-between-emergency-remote-teaching-andonline-learning.

Gaytan, J. and B. McEwen (2007), "Effective online instructional and assessment strategies", American Journal of Distance Education, Vol. 21/3, pp. 117-132, http://dx.doi.org/10.1080/08923640701341653.

Arend, B. (2007), "Course assessment practices and student learning strategies in online courses", Journal of Asynchronous Learning Networks, Vol. 11/4, pp. 3-17.

Alruwais, N., G. Wills and M. Wald (2018), "Advantages and challenges of using e-assessment", International Journal of Information and Education Technology, Vol. 8/1, pp. 34-37.

IAU (2020), "The Impact of Covid-19 on Higher Education around the World", International Association of Universities, Paris, https://www.iauaiu.net/IMG/pdf/iau_covid19 and he survey_report_final_may_2020.pdf.

OECD (2020), "Remote online exams in higher education during the COVID-19 crisis", Education Policies Perspectives, $\quad$ https://www.oecd-ilibrary.org/docserver/f53e2177en.pdf?expires=1621716787\&id=id\&accname=guest\&checksum=CF7276F13A277D4FD271ED4F86 E76F92

Miroslav Beblavý, Sara Baiocco, Zachary Kilhoffer, Mehtap Akgüç, Manon Jacquot (2019), “Index of Readiness for Digital Lifelong Learning", Changing How Europeans Upgrade Their Skills, https://www.ceps.eu/ceps-publications/index-of-readiness-for-digital-lifelong-learning/

Charles Hodges, Stephanie Moore, Barb Lockee, Torrey Trust and Aaron Bond (2020), "The Difference Between Emergency Remote Teaching and Online Learning", Why IT Matters to Higher Education, EDUCASE Review, https://er.educause.edu/articles/2020/3/the-difference-betweenemergency-remote-teaching-and-online-learning

University of Athens Open Courses service. http://opencourses.uoa.gr

Open Delos platform web portal. http://opendelos.org

Open eClass Learning Management System. http://openeclass.org 


\section{Author biographies}

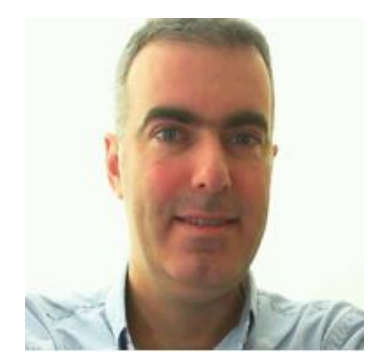

Konstantinos Tsibanis is a Researcher (PhD candidate) in the field of Elearning Strategies and Technologies. He holds a BSc in Applied Mathematics, an MSc in Informatics and an MSc in Management and Economics of Telecommunication Networks. He works as an IT Manager at the National and Kapodistrian University of Athens (Network Operations Centre) and the Greek Academic Network (GUnet), responsible for the design and development of e-learning services. He is highly experienced in designing e-learning services and successfully manages all phases of elearning projects from needs analysis and requirements definition to technology selection, implementation, and training. He is the founder and the person responsible for the design, development and support of the Open eClass platform (openeclass.org), an open source LMS on which the majority of the Higher Educational Institutes in Greece base their e-learning services.

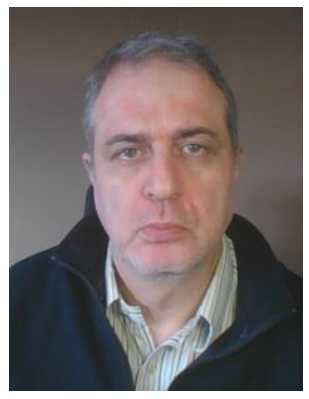

Pantelis Balaouras holds a PhD in Informatics and Telecommunications and a Diploma on Computer Engineering. He has expertise in designing and deploying multimedia based e-learning and communication services, such as video conferencing, video streaming and on demand services, multimedia digital collections, and IPTV services. He is the technical director of GUnet's Support Center for e-learning and media production (mc.gunet.gr) and product engineer for the Open Delos platform (opendelos.org). Dr. Balaouras was the project and technical manager for the nationwide project focusing on the development of open courses and supporting services (project.opencourses.gr), and NKUA's project for developing 250 open courses (opencourses.uoa.gr). 